\title{
Low-Dose Acetazolamide in the Treatment of Premenstrual Dysphoric Disorder: A Case Series
}

\author{
Gabriele Sani ${ }^{1,2} \bowtie$, Georgios D. Kotzalidis ${ }^{1}$, Isabella Panaccione ${ }^{1,3}$, Alessio Simonetti ${ }^{1,2}$, \\ Lavinia De Chiara ${ }^{1,2}$, Antonio Del Casale ${ }^{1}$, Elisa Ambrosi ${ }^{1}$, Flavia Napoletano ${ }^{1,2}$, Delfina Janiri', \\ Emanuela Danese', Nicoletta Girardi', Chiara Rapinesi', Daniele Serata', Giovanni Manfredi'1,2, \\ Alexia E. Koukopoulos ${ }^{1,2}$, Gloria Angeletti ${ }^{1,2}$, Ferdinando Nicoletti ${ }^{3,4}$, and Paolo Girardi ${ }^{1,2,5}$ \\ ${ }^{1}$ NESMOS Department (Neuroscience, Mental Health, and Sensory Organs), Sapienza University, School of Medicine and Psychology, \\ Sant'Andrea Hospital, Rome, Italy \\ ${ }^{2}$ Centro Lucio Bini, Rome, Italy \\ ${ }^{3}$ RRCSS NEUROMED, Pozzilli, Isernia, Italy \\ ${ }^{4}$ Department of Physiology and Pharmacology “Vittorio Erspamer”, Sapienza University, School of Medicine and Psychology, Rome, Italy \\ ${ }^{5}$ Clinica Neuropsichiatrica Villa Rosa, Suore Ospedaliere del Sacro Cuore di Gesù, Viterbo, Italy
}

The treatment of premenstrual dysphoric disorder (PMDD) is far from satisfactory, as there is a high proportion of patients who do not respond to conventional treatment. The antidiuretic sulfonamide, acetazolamide, inhibits carbonic anhydrase and potentiates GABAergic transmission; the latter is putatively involved in PMDD. We therefore tried acetazolamide in a series of women with intractable PMDD. Here, we describe a series of eight women diagnosed with DSM-IV-TR PMDD, five of whom had comorbidity with a mood disorder and one with an anxiety disorder, who were resistant to treatment and responded with symptom disappearance after being added-on 125 $\mathrm{mg} /$ day acetazolamide for 7-10 days prior to menses each month. Patients were free from premenstrual symptoms at the 12-month follow-up. We suggest that acetazolamide may be used to improve symptoms of PMDD in cases not responding to other treatments. GABAergic mechanisms may be involved in counteracting PMDD symptoms.

Psychiatry Investig 2014;11:95-101

Key Words Premenstrual dysphoric disorder, Sulfonamide diuretics, Acetazolamide, GABA transmission.

\section{INTRODUCTION}

Experiencing emotional and physical symptoms during the premenstrual phase is common in most women. More than $80 \%$ of reproductive-age women suffer from symptoms during the luteal phase of their ovarian cycle. ${ }^{1,2}$ Usually these symptoms are mild, however, they can be severe enough to affect social, working and family life in a minority of patients. ${ }^{2-8}$

A premenstrual tension syndrome was recognized in the early ' $30 s^{9}$ and attributed to rejected fantasies of motherhood, but also related to the activity of the corpus luteum. ${ }^{10}$ The syn-

Received: January 14, 2013 Revised: March 18, 2013

Accepted: March 20, 2013 Available online: January 21, 2014

$\triangle$ Correspondence: Gabriele Sani, MD

NESMOS Department (Neuroscience, Mental Health, and Sensory Organs), Sapienza University, School of Medicine and Psychology, UOC Psichiatria, Sant'Andrea Hospital, Via di Grottarossa 1035-1039, 00189 Rome, Italy

Tel: +39-0633775951, Fax: +39-0633775342

E-mail: gabriele.sani@uniroma1.it

(a) This is an Open Access article distributed under the terms of the Creative Commons Attribution Non-Commercial License (http://creativecommons.org/licenses/bync/3.0) which permits unrestricted non-commercial use, distribution, and reproduction in any medium, provided the original work is properly cited. drome concept was further refined and renamed as premenstrual syndrome (PMS) in the early '50s, ${ }^{11}$ but despite this, specific diagnostic criteria were lacking. ${ }^{12}$ In 1987, the DSMIII-R introduced diagnostic criteria for "late luteal phase dysphoric disorder" and clearly defined the syndrome; ${ }^{13}$ this syndrome was re-named as "premenstrual dysphoric disorder" (PMDD) in the DSM-IV. ${ }^{6}$ Less rigorous definitions of PMS were provided by the World Health Organization's International Classification of Diseases (ICD-10), ${ }^{14}$ the American College of Obstetricians and Gynecologists, ${ }^{15}$ and the Royal College of Obstetricians and Gynaecologists. ${ }^{16}$ Recently, a consensus group has proposed new criteria, relevant for research purposes. $^{17}$

Differences in classification criteria for PMS led to significant variations in estimated prevalence; using the restrictive criteria of the American College of Obstetricians and Gynecologists, ${ }^{15} \mathrm{PMDD}$ is considered to affect at least $3-8 \%$ of reproductive-age women, whereas using broader criteria, the prevalence of PMS rises to $30-40 \% .{ }^{18}$

Despite PMDD treatment includes a wide range of thera- 
peutic options, only few of them are backed by clinical evidence. Selective serotonin reuptake inhibitors (SSRIs) proved to be superior to placebo in several studies ${ }^{19,20}$ and have a firstline indication, despite recent questioning of their effectiveness. ${ }^{21}$ Treatment with nonSSRI antidepressants ${ }^{22-24}$ and lithi$\mathrm{um}^{25}$ failed to relieve symptoms. Among anti-anxiety agents, alprazolam obtained inconsistent effects, ${ }^{26-29}$ while buspirone showed weak efficacy. ${ }^{30,31}$ Suppression of ovulation with oral contraceptives like the drospirenone/ethinylestradiol combination, ${ }^{32-34} \mathrm{GnRH}$ agonists, ${ }^{35}$ the synthetic steroid 17alphaethinyl testosterone, ${ }^{36}$ or ovariectomy, ${ }^{37,38}$ significantly reduces or eliminates symptoms. Other treatments include diuretics, such as spironolactone, ${ }^{39}$ and non-steroidal anti-inflammatory drugs (NSAIDs), ${ }^{40,41}$ that are shown to reduce symptoms such as bloating, pain and headache. Nonpharmacological treatments, such as dietary supplements, physical exercise, ${ }^{42}$ and cognitive-behavior therapy ${ }^{43,44}$ may likewise be helpful.

Acetazolamide, like other sulfonamides such as methazolamide, zonisamide and sulthiame, is a potent inhibitor of carbonic anhydrase (CA). CA is an enzyme catalyzing the reversible reaction in which carbon dioxide $\left(\mathrm{CO}_{2}\right)$ and water $\left(\mathrm{H}_{2} \mathrm{O}\right)$ are converted to carbonic acid $\left(\mathrm{H}_{2} \mathrm{CO}_{3}\right)$, which in turn dissociates in hydrogen ion (or proton, $\mathrm{H}^{+}$) and bicarbonate $\left(\mathrm{HCO}_{3}{ }^{-}\right)$. While originally developed as a diuretic drug, acetazolamide has been used to treat seizures since the discovery of the presence in the brain of a specific isoform of carbonic anhydrase, CA VII, ${ }^{45}$ which appears to be involved in the regulation of GABAergic transmission ${ }^{46}$ Interestingly, GABAergic dysfunction appears to be involved in animal paradigms of PMDD. ${ }^{47}$ Approval for its use in epilepsy dates back to 1953. Acetazolamide is primarily used in combination with other antiepileptic medications and also in refractory absence, partial, myoclonic and primary generalized tonic-clonic seizures. ${ }^{48}$ It has also been used to treat catamenial epilepsy. ${ }^{49}$

Acetazolamide has been proved to be effective in the treatment of several other diseases, such as glaucoma ${ }^{50}$ idiopathic intracranial hypertension (pseudotumor cerebri), ${ }^{51}$ mountain sickness, ${ }^{52}$ central sleep apnea, ${ }^{53}$ hypokalemic periodic paralysis. ${ }^{54}$ Interestingly, there are several papers in the literature reporting the efficacy of acetazolamide in the treatment of atypical psychoses,${ }^{55}$ menstrual cycle-related fluctuations in Parkinson's disease ${ }^{56}$ bipolar affective disorders, ${ }^{57}$ and acute mania in a patient with bipolar disorder. ${ }^{58}$

On this basis, we tried acetazolamide as an adjunctive medication in women with or without mood disorders suffering from PMDD symptoms.

\section{CASE}

All patients were personally treated by one of the authors
(G.S.) and were followed for a mean period of 23.1 months (range 10-36, SD 11.24). Six patients had an axis I psychiatric disorder comorbid with DSM-IV-TR Premenstrual Dysphoric Disorder (PMDD), while two had PMDD only. Before making PMDD diagnosis, patients had to fill-out a daily symptom chart ${ }^{59}$ for at least four months. We used the Italian version of Temperament Evaluation of Memphis, Pisa, Paris and San Diego-autoquestionnaire version (TEMPS-A). ${ }^{60}$ No patient was receiving estrogens or progestins. After specific psychiatric drug treatment, all patients had fully recovered from their comorbid psychiatric disorder, but continued to experience PMDD symptoms before the introduction of acetazolamide. All patients took acetazolamide monthly for a 7-to-10day period before menses. All patients signed free, informed consent for both treatment and publication of their cases.

\section{Case 1}

A 34-year-old single, childless Caucasian woman with a cyclothymic premorbid temperament, suffered from a severe form of PMDD since her adolescence. For more than 10 years she had abused substances (mainly cocaine) and alcohol. Her mood was consistently unstable, with bouts of self-inflicted injuries (self-cutting of the whole body), eating disorder (bulimia with self-induced vomiting) and impulsiveness, meeting DSM-IV-TR criteria for Borderline Personality Disorder. She had voluntarily interrupted a pregnancy when she was 32 .

In the last two years, she had stopped drug and alcohol abuse, but her clinical picture remained as before. We instituted therapy with lithium up to $600 \mathrm{mg} /$ day, maintaining lithium blood levels up to $0.6 \mathrm{mEq} / \mathrm{L}$, while slowly titrating lamotrigine up to $200 \mathrm{mg} /$ day.

Her mood stabilized after six months of treatment, with the exception of the period before menses. According to the diary chart, during this period she experienced depressive feelings, severe anxiety, irritability, insomnia, binge eating, desperate crying spells, desire of self-cutting. Her Clinical Global Impressions severity scale score (CGIs) was 6. All symptoms lasted for 7-10 days and disappeared suddenly by the first day of menses. Three months later, we added $125 \mathrm{mg} /$ day acetazolamide, with intermittent monthly intake limited from ten days before the menses to the first day of menses. Since the first month, PMDD symptoms improved significantly (CGIs, 2), while no significant adverse event occurred. However, blood pressure slightly decreased, from 110/80 $\mathrm{mm} \mathrm{Hg}$ to $100 / 70$ $\mathrm{mm} \mathrm{Hg}$. After one year of treatment, the patient continues on add-on acetazolamide and is free from premenstrual symptoms (CGIs=1).

\section{Case 2}

A 29-year-old, single, nulliparous Caucasian woman with 
cyclothymic premorbid temperament and DSM-IV-TR diagnosis of Bipolar Disorder, type II, had severe PMDD since her teens. The bipolar onset may be traced back to age 15, when she had a first depressive episode. Since then, she had four depressive and three hypomanic episodes. She took several antidepressant drugs with little benefit.

Since the onset of PMDD, she had developed feelings of worthlessness and emptiness, a bleak outlook of future, and an imminent sense of death.

We treated her bipolar disorder with lithium up to $450 \mathrm{mg} /$ day (lithium blood levels, up to $0.7 \mathrm{mEq} / \mathrm{L}$ ) and oxcarbazepine up to $600 \mathrm{mg} /$ day. Her mood stabilized after four months of treatment. Nevertheless, as emerging from the daily diary, important PMDD symptoms persisted. During the late luteal phase of the menstrual cycle, she was profoundly depressive, hopeless, hypersensitive and emotional, irritable, and unable to make any plan for the future (CGIs, 6). Acetazolamide 125 $\mathrm{mg}$ /day was added. The patient took the medication monthly for a 10-day period before menses. PMDD symptoms subsided soon (CGIs, 1). After three months of treatment, the patient stated she was living one more week per month compared to before. No side effects emerged. Improvement still persists at the 12-month follow-up.

\section{Case 3}

A 31-year-old, single, nulliparous Caucasian woman with cyclothymic premorbid temperament and DSM-IV-TR Bipolar Disorder, type II, had suffered from PMDD since her adolescence. PMDD was characterized by depressive mood, apathy, hypersomnia, anxiety, severe irritability and inner tension, impossibility to concentrate, fatigue, loss of interest in normal activities, crying, and severe binge eating. Her bipolar onset dates back to her twenties, when she presented with a first hypomanic episode. Since then, she had three depressive and four hypomanic episodes. She sporadically took antidepressant drugs.

We introduced lamotrigine up to $150 \mathrm{mg} /$ day and immediate release quetiapine $100 \mathrm{mg} /$ day to treat her mood disorder. Bipolar symptoms subsided after eight months of treatment, but PMDD persisted. On the diary, she reported that the above described picture of PMDD emerged during the pre-menstrual phase (CGIs, 5) and abruptly disappeared with menses. We added $125 \mathrm{mg} /$ day acetazolamide. After the second month of treatment, PMDD started to improve, and had completely subsided by the fourth month of treatment (CGIs, 1). No side effects were reported.

One year later, the patient was fully asymptomatic. However, when she skipped acetazolamide one month, she re-experienced exactly the same PMDD syndrome as before. The next month, the patient reintroduced treatment, and this was fol- lowed by complete symptom resolution.

\section{Case 4}

A 30-year-old, single, nulliparous Caucasian woman with hyperthymic premorbid temperament and DSM-IV-TR recurrent major depressive disorder since age 20, had PMDD preceding her mood disorder by two years. A total of four depressive episodes occurred in ten years; these were characterized by depressive mood, initial insomnia, restlessness, and anxiety, but also by mixed features, such as racing and crowded thoughts, increased energy level, goal directedness, and inner tension. She had received trials with selective serotonin reuptake inhibitors (SSRIs).

We treated her for her mood disorder with oral amitriptyline, $50 \mathrm{mg} /$ day, and oxcarbazepine, titrated to $600 \mathrm{mg} /$ day. After three months of treatment, her mood stabilized. During the pre-menstrual period, however, she continued to experience low mood, hypersomnia, fatigue, anxiety, irritability, feeling of being overwhelmed, and concentration difficulties (CGIs, 5). We added acetazolamide $125 \mathrm{mg}$ /day, for ten days before menses. After the first month of treatment, PMDD improved, resolving completely by the second month of treatment (CGIs, 1). No side effects occurred. After one-and-a-half year of add-on acetazolamide the patient has no premenstrual symptoms (CGIs=1).

\section{Case 5}

A 35-year-old, Caucasian, woman with two children of 9 and 8 years of age, with a cyclothymic temperament and without a DSM-IV-TR axis I diagnosis, had suffered since adolescence from PMDD, characterized by mood swings, severe irritability, desperate crying spells, hopelessness and inner tension during the days immediately preceding menstruation. The patient was psychotropic medication-naïve. PMDD was absent during pregnancies.

The patient filled-out the daily symptom diary for three consecutive months and reported the above-mentioned symptoms during the 10 days before menses (CGIs, 6). Acetazolamide $125 \mathrm{mg} /$ day was added during the critical days. Right after the first month of treatment she no more experienced the usual symptomatology (CGIs, 1), and reported no side effect. When she suspended premenstrual treatment with acetazolamide for two months PMDD reappeared as before. PMDD resolved completely when treatment was initiated again. No side effects occurred. The patient has already completed 14 months with add-on acetazolamide and is fully asymptomatic (CGIs=1).

\section{Case 6}

A 43-year-old, single, nulliparous Caucasian woman with 
a premorbid cyclothymic temperament developed since early adulthood intermittent periods of unpredictable mood fluctuations, causing her problems in her personal and professional life and leading to severe impairment of the social and work domains. She received DSM-IV-TR diagnosis of Cyclothymic Disorder. Her PMDD had its onset at early puberty, with depressive mood, inner tension, affective lability, decreased interest in usually pleasurable activities, irritability, and sense of being out of control. Symptoms occurred during the luteal phase, some days after ovulation, and ended few days after onset of menses. She described this intense and painful state as "the worst pain ever experienced".

She received gabapentin $600 \mathrm{mg} /$ day. The amplitude of mood swings diminished from the first month, with mood reaching stabilization after five months of treatment. Nevertheless, the diary completed during follow-up showed that treatment was ineffective in reducing the luteal phase symptoms (CGIs, 7). Premenstrual symptom persistence for more than two consecutive cycles allowed us to diagnose PMDD. We added $125 \mathrm{mg} /$ day acetazolamide during the critical days. Symptoms improved quickly during the next month (CGIs, 2 ), leading to complete remission within three months. No side effects were reported whatsoever, and the patient is still asymptomatic after twelve months of add on acetazolamide (CGIs=1).

\section{Case 7}

A 39-year-old, single, nulliparous Caucasian woman, with cyclothymic/anxious temperament, suffered from severe PMDD since the age of 12 . The premenstrual syndrome consisted in depressed mood, anxiety, difficulty in concentrating, and decreased interest in usually pleasurable daily activities.

At age 30, she began suffering from episodes of tachycardia, sweating, tremors, feelings of choking, and wheezing. Symptoms recurred frequently through the following years, forcing her to ask for a companion when she had to leave home or for activities like driving a car. This led to impaired social and working life. She received a diagnosis of DSM-IV panic disorder with agoraphobia. She tried several antidepressants, with no apparent benefit. When she came to our attention, we introduced $200 \mathrm{mg} /$ day gabapentin and $0.5 \mathrm{mg} /$ day clonazepam, while gradually discontinuing the SSRI antidepressant she was taking. Frequency and intensity of panic attacks diminished, to disappear completely after four months. Nevertheless, according to the daily diary, symptoms beginning typically few days after ovulation and ending with onset of menses remained unchanged (CGIs, 6). Hence we added during the luteal phase, i.e., 10 days before menses, $125 \mathrm{mg}$ /day acetazolamide. The following month premenstrual symptoms improved (CGIs, 2) and completely disappeared after three months of treatment. She reported no side effects. More than one year after the introduction of add-on acetazolamide, the patient is premenstrual symptom-free (CGIs, 1).

\section{Case 8}

A 32-year-old, Caucasian, nulliparous woman, with cyclothymic premorbid temperament and without a DSM-IV-TR axis I diagnosis, had suffered since adolescence from PMDD, characterized by severe irritability, mood swings, inner tension, desire of "being elsewhere", desperate crying during the days immediately preceding the menstruation. The patient was psychotropic medication-naïve.

The patient filled-out the daily symptom diary for three consecutive months and reported the above-mentioned symptoms during the premenstrual phase (CGIs, 6). Acetazolamide $125 \mathrm{mg} /$ day was added during the critical days. Right after the first two months of treatment she no more experienced the usual symptomatology (CGIs, 1), and reported no side effect.

After four months of treatment she stopped taking the medication and she re-experienced exactly the same PMDD syndrome as before. She resumed acetazolamide intake as scheduled before, and symptoms disappeared once more; after further nine months of treatment, the patients manifests no premenstrual symptoms (CGIs, 1).

\section{DISCUSSION}

Our observations show dramatic efficacy of low-dose acetazolamide in preventing PMDD symptom onset. The exact mechanism through which acetazolamide exerts this heretofore not described effect is not known; however we can speculate that it might relate to the antiepileptic action of this molecule. Epileptic seizures are caused by abnormal, hypersynchronous neuronal discharges originating in specific group of neurons (focus), usually located in the cerebral cortex, and then spread to other parts of the brain. Despite this phenomenon has been widely studied since long time, the exact neuronal mechanisms by which seizures are initiated are not entirely understood. One of the most common theories is that seizures are due to an excessive excitability of neurons, which is probably caused by ionic imbalance between the concentrations of depolarizing excitatory ions (sodium and calcium influx) and the hyperpolarizing inhibitor ions (chloride influx and potassium efflux). Also, an aberrant regulation of the excitatory (glutamate) and inhibitory (GABA) neurotransmission may contribute to the genesis of this phenomenon. Interestingly, these amino acids show a complex interplay in the central nervous system ${ }^{61}$ which is regulated by steroids and are both putatively involved in mood disorders; ${ }^{62}$ furthermore, both these mechanisms might be influenced by the action of 
CA. In fact, low extracellular concentration of protons is found to be related to high excitatory activity, whereas high concentrations of protons suppress the excitatory activity of the NMDA receptors. CA increases the intracellular concentration of protons by catalyzing the formation of carbonic acid, which in turn dissociates in a proton and carbonic acid; therefore, the inhibition of CA might provide a possible explanation for the anticonvulsant effects of acetazolamide. It should be recalled that premenstrual symptoms often co-occur with bipolar disorder, ${ }^{63}$ and that in our sample the most often comorbid condition was bipolar disorder.

It is unclear why our patients all responded to low-dose acetazolamide while not responding to other GABAergic drugs like topiramate and oxcarbazepine. While there is no evidence that oxcarbazepine interferes with CA, topiramate is well-known to inhibit several CA isoenzymes. ${ }^{64,65}$ It is unknown whether this has to do with a cyclical pattern of CA concentration, as such pattern has not been found to occur in the erythrocytes of healthy women during their menstrual cycle. ${ }^{66} \mathrm{How}-$ ever, acetazolamide proved to be effective in catamenial epilepsy, a condition that shares with PMDD its temporal pattern. ${ }^{49}$ In this study, many patients improved considerably on acetazolamide, which often was given continuously; the authors argued that a continuous pattern could have induced tolerance to the therapeutic effect of acetazolamide, proposing an administration pattern similar to ours or every other day. In fact, our patients receiving oxcarbazepine did so on a continuous schedule.

Antiepileptic drugs, such as valproic acid, carbamazepine and topiramate are commonly used as mood stabilizers in a variety of psychiatric disorders. It is possible to speculate that the anticonvulsant activity of acetazolamide, like that of other anticonvulsants, has a mood stabilizing effect, even at a subclinical level. We propose premorbid temperament to be important in the pathogenesis of PMDD. According to the DSMIV criterion C for PMDD, the disturbance is not merely an exacerbation of the symptoms of another disorder, such as major depression disorder, panic disorder, dysthymic disorder or a personality disorder (although it may be superimposed on any of these disorders). All our patients met this criterion.

It could be that both the primary psychiatric disorder and PMDD are rooted in the same constitutional realm, i.e., temperament. Temperament refers to stable behavioral traits with a strong affective hue.

Cyclothymic temperament is the most unstable and the most likely to be involved in cycling course induced by external stimuli ${ }^{67}$ and mixed affective states. ${ }^{68}$ It was shared by seven out of our eight patients, while only one patient had hyperthymic temperament. We believe that hormonal changes during the luteal phase, which were shown to be associated with PMDD symptoms $s^{69,70}$ may affect the nervous system of patients with unstable-mood temperaments to a greater extent than other, more stable, temperaments, thus triggering low mood, affective instability, irritability, anxiety, and other PMDD symptoms. Acetazolamide used as monotherapy in milder PMDD forms and as add-on in more severe cases could prevent PMDD symptoms by ameliorating the constitutional and temperamental instability of such patients. This conjecture could provide impetus for future research.

\section{Acknowledgments}

We gratefully acknowledge the contribution of the Librarians of the School of Medicine and Psychology of Sapienza University, Ms. Mimma Ariano, Ms. Felicia Proietti and the late Tiziana Mattei, in helping us localising relevant literature. We also thank Ms. Lucilla Martinelli for reviewing the manuscript and offering precious consultation.

\section{REFERENCES}

1. Johnson SR, McChesney C, Bean JA. Epidemiology of premenstrual symptoms in a nonclinical sample. I. Prevalence, natural history and help-seeking behavior. J Reprod Med 1988;33:340-346.

2. Hylan T, Sundell K, Judge R. The impact of premenstrual symptomatology on functioning and treatment-seeking behavior: experience from the United States, United Kingdom, and France. J Womens Health Gend Based Med 1999;8:1043-1052.

3. Borenstein JE, Dean BB, Endicott J, Wong J, Brown C, Dickerson V, et al. Health and economic impact of the premenstrual syndrome. J Reprod Med 2003;48:515-524.

4. Borenstein JE, Dean BB, Leifke E, Korner P, Yonkers KA. Differences in symptom scores and health outcomes in premenstrual syndrome. J Womens Health (Larchmt) 2007;16:1139-1144.

5. Yang M, Wallenstein G, Hagan M, Guo A, Chang J, Kornstein S. Burden of premenstrual dysphoric disorder on health-related quality of life. J Womens Health (Larchmt) 2008;17:113-121.

6. American Psychiatric Association. Diagnostic and Statistical Manual of Mental Disorders, 4th Edition (DSM-IV). Washington, DC: American Psychiatric Association; 1994.

7. Yonkers KA, Halbreich U, Freeman E, Brown C, Endicott J, Frank E, et al. Symptomatic improvement of premenstrual dysphoric disorder with sertraline treatment. A randomized controlled trial. Sertraline Premenstrual Dysphoric Collaborative Study Group. JAMA 1997;278: 983-988.

8. Pearlstein TB, Halbreich U, Batzar ED, Brown CS, Endicott J, Frank E, et al. Psychosocial functioning in women with premenstrual dysphoric disorder before and after treatment with sertraline or placebo. J Clin Psychiatry 2000;61:101-109.

9. Frank RT. The hormonal causes of premenstrual tension. Arch Neurol Psychiatry 1931;26:1053-1057.

10. Horney K. Die prämenstruellen Verstimmungen. Zeitschrift für psychoanalytische Pädagogik 1931;5:1-7.

11. Greene R, Dalton K. The premenstrual syndrome. Br Med J 1953;1: 1007-1014.

12. Halbreich U, Backstrom T, Eriksson E, O’Brien S, Calil H, Ceskova E, et al. Clinical diagnostic criteria for premenstrual syndrome and guidelines for their quantification for research studies. Gynecol Endocrinol 2007;23:123-130.

13. American Psychiatric Association. Diagnostic and Statistical Manual of Mental Disorders. 3rd Edition-Revised (DSM-III-R). Washington, DC: American Psychiatric Association; 1987.

14. World Health Organization. ICD-10: International Classification of Diseases and Related Health Problems (Tenth Revision). Geneva: World 
Health Organization; 1992.

15. American College of Obstetricians and Gynecologists. Premenstrual Syndrome. ACOG Practice Bulletin no 15. Washington, DC: American College of Obstetricians and Gynecologists; 2000.

16. Royal College of Obstetricians and Gynaecologists. Management of Premenstrual Syndrome Green-top Guideline No 48. London: Royal College of Obstetricians and Gynaecologists; 2007.

17. O’Brien PM, Bäckström T, Brown C, Dennerstein L, Endicott J, Epperson $\mathrm{CN}$, et al. Towards a consensus on diagnostic criteria, measurement and trial design of the premenstrual disorders: the ISPMD Montreal consensus. Arch Womens Ment Health 2011;14:13-21.

18. Pearlstein T. Prevalence, Impact on Morbidity and Burden of Disease. In: O’Brien PMS, Rapkin A, Schmidt P, Editors. The Premenstrual Syndromes: PMS and PMDD. London: Informa Healthcare, 2007, p. 37-47.

19. Shah NR, Jones JB, Aperi J, Shemtov R, Karne A, Borenstein J. Selective serotonin reuptake inhibitors for premenstrual syndrome and premenstrual dysphoric disorder: a meta-analysis. Obstet Gynecol 2008; 111:1175-1182.

20. Brown J, O’Brien PM, Marjoribanks J, Wyatt K. Selective serotonin reuptake inhibitors for premenstrual syndrome. Cochrane Database Syst Rev 2009;(2):CD001396.

21. Halbreich U. Selective serotonin reuptake inhibitors and initial oral contraceptives for the treatment of PMDD: effective but not enough. CNS Spectr 2008; 13:566-572.

22. Eriksson E, Hedberg M, Andersch B, Sundblad C. The serotonin reuptake inhibitor paroxetine is superior to the noradrenaline reuptake inhibitor maprotiline in the treatment of premenstrual syndrome. Neuropsychopharmacology 1995;12:167-176.

23. Pearlstein TB, Stone AB, Lund SA, Scheft H, Zlotnick C, Brown WA. Comparison of fluoxetine, buproprion, and placebo in the treatment of premenstrual dysphoric disorder. J Clin Psychopharmacol 1997;17: 261-266.

24. Freeman EW, Rickels K, Sondheimer SJ, Polansky M. Differential response to antidepressants in women with premenstrual syndrome/premenstrual dysphoric disorder: a randomized controlled trial. Arch Gen Psychiatry 1999;56:932-939.

25. Steiner M, Haskett RF, Osmun JN, Carroll BJ. Treatment of premenstrual tension with lithium carbonate. A pilot study. Acta Psychiatr Scand 1980;61:96-102.

26. Smith S, Rinehart JS, Ruddock VE, Schiff I. Treatment of premenstrual syndrome with alprazolam: results of a double-blind, placebo-controlled, randomized crossover clinical trial. Obstet Gynecol 1987;70: 37-43.

27. Harrison WM, Endicott J, Nee J. Treatment of premenstrual dysphoria with alprazolam. A controlled study. Arch Gen Psychiatry 1990;47:270275.

28. Freeman EW, Rickels K, Sondheimer SJ, Polansky M. A double-blind trail of oral progesterone, alprazolam, and placebo in treatment of severe premenstrual syndrome. JAMA 1995;274:51-57.

29. Schmidt P, Grover G, Rubinow D. Alprazolam in the treatment of premenstrual syndrome. A double-blind, placebo-controlled trial. Arch Gen Psychiatry 1993;50:467-473.

30. Landen M, Eriksson O, Sundblad C, Andersch B, Naessen T, Erikkson E. Compounds with affinity for serotonergic receptors in the treatment of premenstrual dysphoria: a comparison of buspirone, nefazodone and placebo. Psychopharmacology (Berl) 2001;155:292-298.

31. Rickels K, Freeman E, Sondheimer S. Buspirone in treatment of premenstrual syndrome. Lancet 1989;1:777.

32. Freeman EW. Evaluation of a unique oral contraceptive (Yasmin) in the management of premenstrual dysphoric disorder. Eur J Contracept Reprod Health Care 2002;7(suppl 3):27-34.

33. Lopez LM, Kaptein AA, Helmerhorst FM. Oral contraceptives containing drospirenone for premenstrual syndrome. Cochrane Database Syst Rev 2009;(2):CD006586.

34. Rapkin AJ, Winer SA. Drospirenone: a novel progestin. Expert Opin
Pharmacother 2007;8:989-999.

35. Sundström I, Nyberg S, Bixo M, Hammarbäck S, Bäckström T. Treatment of premenstrual syndrome with gonadotropin-releasing hormone agonist in a low dose regimen. Acta Obstet Gynecol Scand 1999;78: 891-899.

36. Halbreich U, Rojansky N, Palter S. Elimination of ovulation and menstrual cyclicity (with danazol) improves dysphoric premenstrual syndromes. Fertil Steril 1991;56:1066-1069.

37. Casper RF, Hearn MT. The effect of hysterectomy and bilateral oophorectomy in women with severe premenstrual syndrome. Am J Obstet Gynecol 1990;162:105-109.

38. Casson P, Hahn PM, Van Vugt DA, Reid RL. Lasting response to ovariectomy in severe intractable premenstrual syndrome. Am J Obstet Gynecol 1990;162:99-105.

39. Wang M, Hammarbäck S, Lindhe BA, Bäckström T. Treatment of premenstrual syndrome by spironolactone: a double-blind, placebo-controlled study. Acta Obstet Gynecol Scand 1995;74:803-808.

40. Mira M, McNeil D, Fraser IS, Vizzard J, Abraham S. Mefenamic acid in the treatment of premenstrual syndrome. Obstet Gynecol 1986;68: 395-398.

41. Facchinetti F, Fioroni L, Sances G, Romano G, Nappi G, Genazzani AR. Naproxen sodium in the treatment of premenstrual symptoms. A placebo-controlled study. Gynecol Obstet Invest 1989;28:205-208.

42. Steege JF, Blumenthal JA. The effects of aerobic exercise on premenstrual symptoms in middle-aged women: a preliminary study. J Psychosom Res 1993;37:127-133.

43. Blake F, Salkovskis P, Gath D, Day A, Garrod A. Cognitive therapy for premenstrual syndrome: a controlled trial. J Psychosom Res 1998;45: 307-318.

44. Christensen AP, Oei TP. The efficacy of cognitive behaviour therapy in treating premenstrual dysphoric changes. J Affect Disord 1995;33:57-63.

45. Halmi P, Parkkila S, Honkaniemi J. Expression of carbonic anhydrases II, IV, VII, VIII and XII in rat brain after kainic acid induced status epilepticus. Neurochem Int 2006;48:24-30.

46. Thiry A, Masereel B, Dogné JM, Supuran CT, Wouters J, Michaux C. Exploration of the binding mode of indanesulfonamides as selective inhibitors of human carbonic anhydrase type VII by targeting Lys 91 . ChemMedChem 2007;2:1273-1280.

47. Lovick TA. Plasticity of GABAA receptor subunit expression during the oestrous cycle of the rat: implications for premenstrual syndrome in women. Exp Physiol 2006;91:655-660.

48. Reiss WG, Oles KS. Acetazolamide in the treatment of seizures. Ann Pharmacother 1996;30:514-519.

49. Lim LL, Foldvary N, Mascha E, Lee J. Acetazolamide in women with catamenial epilepsy. Epilepsia 2001;42:746-749.

50. Stewart WC. Perspectives in the medical treatment of glaucoma. Curr Opin Ophthalmol 1999;10:99-108.

51. Wandstrat TL, Phillips J. Pseudotumor cerebri responsive to acetazolamide. Ann Pharmacother 1995;29:318.

52. Richalet JP, Rivera M, Bouchet P, Chirinos E, Onnen I, Petitjean O, et al. Acetazolamide: a treatment for chronic mountain sickness. Am J Respir Crit Care Med 2005;172:1427-1433.

53. White DP, Zwillich CW, Pickett CK, Douglas NJ, Findley LJ, Weil JV. Central sleep apnea. Improvement with acetazolamide therapy. Arch Intern Med 1982;142:1816-1819.

54. Matthews E, Portaro S, Ke Q, Sud R, Haworth A, Davis MB, et al. Acetazolamide efficacy in hypokalemic periodic paralysis and the predictive role of genotype. Neurology 2011;77:1960-1964.

55. Inoue H, Hazama H, Hamazoe K, Ichikawa M, Omura F, Fukuma E, et al. Antipsychotic and prophylactic effects of acetazolamide (Diamox) on atypical psychosis. Folia Psychiatr Neurol Jpn 1984;38:425-436.

56. Factor SA. Acetazolamide therapy of menstrual-related fluctuations in Parkinson's disease. Mov Disord 1993;8:240-241.

57. Hayes SG. Acetazolamide in bipolar affective disorders. Ann Clin Psychiatry 1994;6:91-98. 
58. Brandt C, Grunze H, Normann C, Walden J. Acetazolamide in the treatment of acute mania. A case report. Neuropsychobiology 1998;38:202203.

59. Freeman EW, DeRubeis RJ, Rickels K. Reliability and validity of a daily diary for premenstrual syndrome. Psychiatry Res 1996;65:97-106.

60. Pompili M, Girardi P, Tatarelli R, Iliceto P, De Pisa E, Tondo L, et al. TEMPS-A (Rome): psychometric validation of affective temperaments in clinically well subjects in mid- and south Italy. J Affect Disord 2008; 107:63-75.

61. Kendell SF, Krystal JH, Sanacora G. GABA and glutamate systems as therapeutic targets in depression and mood disorders. Expert Opin Ther Targets 2005;9:153-168.

62. Kim BG, Cho JH, Choi IS, Lee MG, Jang IS. Modulation of presynaptic GABA(A) receptors by endogenous neurosteroids. Br J Pharmacol 2011; 164:1698-1710.

63. Choi J, Baek JH, Noh J, Kim JS, Choi JS, Ha K, et al. Association of seasonality and premenstrual symptoms in bipolar I and bipolar II disorders. J Affect Disord 2011;129:313-316.
64. Dodgson SJ, Shank RP, Maryanoff BE. Topiramate as an inhibitor of carbonic anhydrase isoenzymes. Epilepsia 2000;41(Suppl 1):S35-S39.

65. Shank RP, Smith-Swintosky VL, Maryanoff BE. Carbonic anhydrase inhibition. Insight into the characteristics of zonisamide, topiramate, and the sulfamide cognate of topiramate. J Enzyme Inhib Med Chem 2008; 23:271-276.

66. Koukopoulos A, Sani G, Koukopoulos AE, Albert MJ, Girardi P, Tatarelli R. Endogenous and exogenous cyclicity and temperament in bipolar disorder: review, new data and hypotheses. J Affect Disord 2006; 96:165-175

67. Koukopoulos A, Sani G, Koukopoulos AE, Manfredi G, Pacchiarotti I, Girardi P. Melancholia agitata and mixed depression. Acta Psychiatr Scand Suppl 2007;433:50-57.

68. Joffe H, Cohen LS. Estrogen, serotonin, and mood disturbance: where is the therapeutic bridge? Biol Psychiatry 1998;44:798-811.

69. Steiner M, Dunn E, Born L. Hormones and mood: from menarche to menopause and beyond. J Affect Disord 2003;74:67-83. 